Proceedings of the 2018 Winter Simulation Conference

M. Rabe, A.A. Juan, N. Mustafee, A. Skoogh, S. Jain, and B. Johansson, eds.

\title{
HYBRID USER EXPERIENCE (UX) MODELLING IN A HERITAGE SETTING
}

\author{
Nada Nasser Al Subhi \\ David Bell \\ Department of Computer Science \\ Brunel University London \\ Uxbridge , UB8 3PH, UK
}

\begin{abstract}
Visitor expectations continually evolve as new forms of technology mediate ever more personalized interactions, not only within the museum, but also virtually around the physical environment. Designing visitor journey experiences that support visitor heterogeneity are complex. Consequently, it is difficult for museum management and collection managers to respond effectively in their design of heritage experiences. Understanding human behavior at scale is challenging, often explored in other disciplines by simulating generic process models and scenarios. Creating experiences for cultural heritage persona remains a challenge because no clear methodology currently exists. This paper proposes a methodological framework supporting museum and collection managers in their design and simulation of heritage experiences. Clear classification of visitors and journeys is undertaken at the outset. Journey mapping is used as a modeling primitive for both agent and system dynamic modeling.
\end{abstract}

\section{INTRODUCTION}

While real world digital heritage experiences are rich and significant, a parallel interactive experience can support many museum objects, stories and interlinked locations. Small variations in this interaction may then have a major impact on the overall visitor experience. To understand these effects, higher-quality experience design is promoted as a basis to better motivate visitor interaction and offer further opportunities for enhancing engagement with heritage. Technological democratization in recent times has driven both opportunities and expectations for the visualization of heritage artefacts both inside and outside a museum (Hincapie et al. 2016; Padilla-Meléndez and del Águila-Obra 2013; Bakhshi 2013; Evans 2013) A concern for Dorset County Museum (DCM) in the UK was that a high proportion of visitors did not visit Maiden Castle after the museum visit despite it being an important historical landscape (one of the largest Iron Age hill forts in Europe) and source location for many of their artefacts.

Little quality of experience $(\mathrm{QoE})$ research has been undertaken in the heritage sector. Consequently, limited methodological theory or design practice has emerged or been tested. Further research is required, to understand the differing aspects of visitor motivation. Understanding the viability and benefit of creating varied experiential journeys for heritage visitors from a wider stakeholder perspective. Our research is carried out linking DCM, an independent museum, with the local landscape in order to provide simulation supported design methods that motivate visitors to travel to heritage locations in the natural landscape, in particular those locations with links to museum artefacts. 


\section{AlSubhi and Bell}

Earlier work (Al Subhi et al. 2015) highlighted a research gap with respect to the process of designing experiences that better engage visitors. Exploring with visitors these various influences that act to shape their aspirations and choices. This research contributes to the heritage technology and modeling literature by providing user experience (UX) based approaches to help stakeholders and museum workers to design and simulate effective heritage experiences. This research also highlights the implications of visitor experience by using design thinking tools in a historical landscape alongside unique proposition and branding in the heritage domain that is able to persuade visitors to visit interlinked locations (e.g. places where artefacts were found). Our design research paper aims to develop a methodological approach for supporting heritage stakeholders to design innovative journey experiences in a systematic manner. A hybrid approach combing agent based models of the wider landscape with system dynamics (SD) being used to explore the potential effects of experience design using a "modelling for learning" approach combining smaller models (Barlas 1996). The combination of modelling paradigms is able to "symbiotically enhance each other's capabilities" (Chahal and Eldabi 2008). The purpose of this approach is to support team reasoning and learning - synthesizing design and system thinking and underpinned by scenario planning. Such models help in understanding experience phenomena allowing comprehension of unintentional consequences of complex adaptive systems. This paper presents a real-world scenario where stakeholders explore a school visit context using hybrid techniques to "generate a phenomenon without pre-supposing it is the best way to understand it, and this is best done in a simulation" (Bishai et al. 2014).

\section{BACKGROUND}

A substantial amount of research on persuasion technology and end users exists, typically focusing on education or health (Halttu et al. 2015; Oinas-Kukkonen 2013; Fogg 2009; Oinas-Kukkonen and Harjumaa 2008; Dillard and Pfau 2002; Fogg et al. 2002). Little research has looked at the use of such technology in encouraging visits to historical locations. Therefore, encouraging visitors to participate in such experiences aligns the needs of human beings and the natural world. Such an approach may be provided by Design Thinking (DT) and builds upon design conceptualizations by wider stakeholder groups (Brown 2009). Many design methods and tools utilize DT procedures and thereby enhance innovations in teams, comprised of both designers and non-designers. One of the advantages of using DT is that diverse stakeholders can become more enthusiastic about design processes (Chasanidou et al. 2015). A number of DT reviews exist (Bae et al. 2014; Alves and Nunes 2013; García et al. 2013), but these lack more pragmatic rules and guidelines on the how best to cultivate innovation with DT strategies and methods that could be utilized by groups of non-designer, including in a heritage setting (Chasanidou et al. 2015).

Simulation in its varied forms has been actively applied in the heritage sector, particularly museums. Fishwick used simulation as means to learn about and better understand museum artefacts (Fishwick 2016). Traditional agent approaches have been used for visitor movement around museums uncovering optimal visitor numbers and associated emergency movement scenarios (Pluchino et al. 2014). Lighting models have been simulation in order to determine the natural lighting when exhibiting art (Kim and Chung 2011).

The adoption of different design perspectives is expected to increase performance in terms of the quality of decision-making or innovativeness problem-solving (West et al. 2003). A team first needs to expand their reasoning, more divergent, and thereby supporting varied contributions. This imaginative aspect of the innovation process usually brings about a satisfactory solution to a real problem (Brown 2009 and Gurteen 1998). Choosing the correct tools is without doubt important for powerful decision-making and communication in a multidisciplinary team. The tools can be physical (for example, a pen, paper, and whiteboard), or programming devices (software tools) with rich representation that support the DT procedure/process. The tools can also be utilized to help a team adopt a new perspective on design tasks, or to visualize the system's complexity. Countless design methods and tools encourage the DT innovation 


\section{AlSubhi and Bell}

process. Alves and Nunes (2013) overviewed diverse sources from both industry and the academia - see Figure 1.

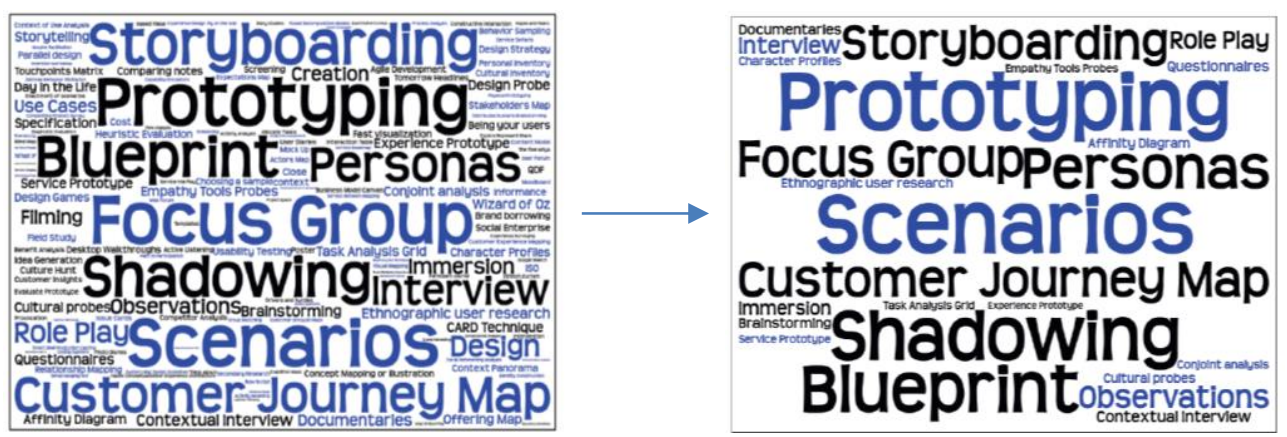

Figure 1: UX Methods and tools - adapted from Aves and Nunes (2013).

Alves and Nunes (2013) group applicable methods based on: 1) the motivation to use the tool; 2) the audience; 3) the targeted content; 4) the representations used; 5) the activities in the design process; and 6) the location where the method or tool likely takes place. Personas, customer journey maps and scenario are chosen for our heritage domain, supporting both agent and system dynamics modelling.

\section{EXPERIENCE DESIGN}

\subsection{UK Museum}

Experience design aims to increase the number of visitors to Dorset County Museum in the UK and its surrounding environment (Figure 2). The museum is where many older people and families represent the main visitors groups - with fewer teenagers visiting the museum. Therefore, one of the main objectives of the design journey is to increase the number of visitors in this muesum and attract a wider demographic, including teenagers. Some context is provided before detailing the methodological framework.
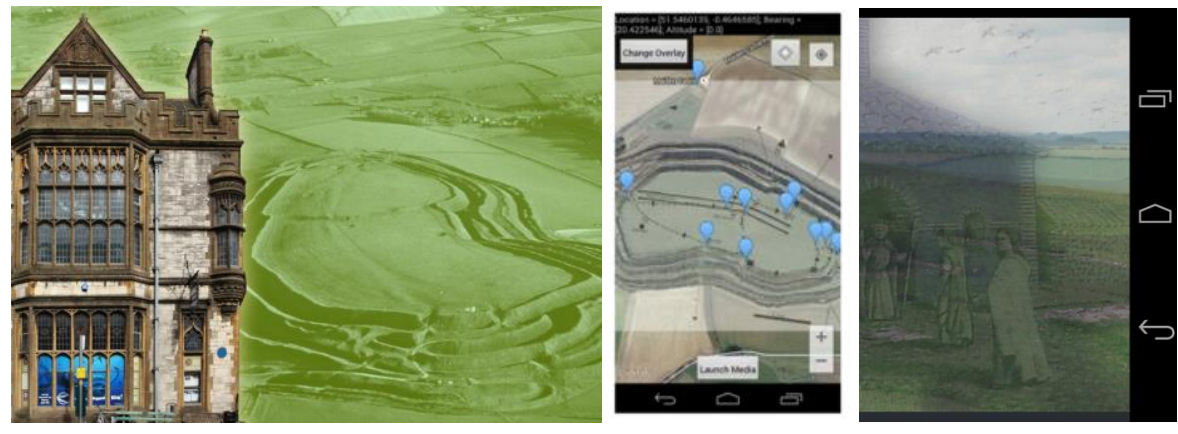

Figure 2: Dorset County Museum, Maiden Castle and iSEE App.

As part of this study, a prototype was built under the iSEE project at Brunel University London in coordination with the DCM to explore visitor experience. The prototype was based on a quantitative research study conducted with visitors to both DCM and Maiden Castle (Al Subhi et al. 2015). This prototype was tested in the field as a demonstration of how physical heritage can be sited (in digital form) within the physical landscape and experienced using location based modelling. In basic terms, the visitor is able to view the map on a smartphone related to their specific location (including both current and historical representations). Tags present a number of touchpoints. On selection, a pop-up provides information including video, photos or audio about a fact/scenario/incident related to that specific location (Figure 2). 


\section{AlSubhi and Bell}

In one example, an archaeologist talks about a specific museum artefact found at the site with supporting imagery. However, this technology focused construct did not fully engage the wider stakeholder community in its design, and followed more traditional software engineering approaches.

\subsection{Modeling Heritage User Experience}

Visitor journeys include context about the experience in which the designer employ interactions. For example, in order to design a journey, the designer should consider which device(s) (e.g. smartphones, tablets) to use and study of the visitor environment, business and community surrounding the journey. Secondly, it is important to consider the different goals of the visit taking into account personalizing the journey. Significant elements of interactivity and action are also considered. Finally, choice of media, as the experienced designer should focus on the media qualities composing the multimedia quality and the integration functions for multimedia (Floris et al. 2014). As discussed earlier, human elements were not included in the taxonomy, since they influence and are influenced by all components.

Von Alan et al. (2004) design science research approach will be followed. Design science research take the form of constructs, models, methods and/or instantiation (March and Smith 1995). This paper investigates how simulation is able to more effectively support the design of visitor journeys and experiences using jouney mapping as modeling primative - adding hybrid simulation (system thinking) to design thinking. This methodology allows designers to work closely with the stakeholders and identify interactions (touch points), create solutions and evaluate them, and as a result, solve problems, support process building and artifact analysis. In addition, many design methods and tools encourage design thinking and encourage innovations within teams, comprising of both designers and non-designers. In this research, persona and CJMs are selected as design thinking methods. The criteria for picking these methods lie in their visualization techniques and capacity to enhance communication inside multidisciplinary teams, additionally in their straightforwardness when used with non-specialists (Chasanidou et al. 2014). We introduce an approach to design journey experiences using agent modeling and system dynamics including causal loop diagrams (CLD) and stock-flow models (SFM) from visitor journey maps (VJM). The framework below describes the design and simulation processes (Figure 3).

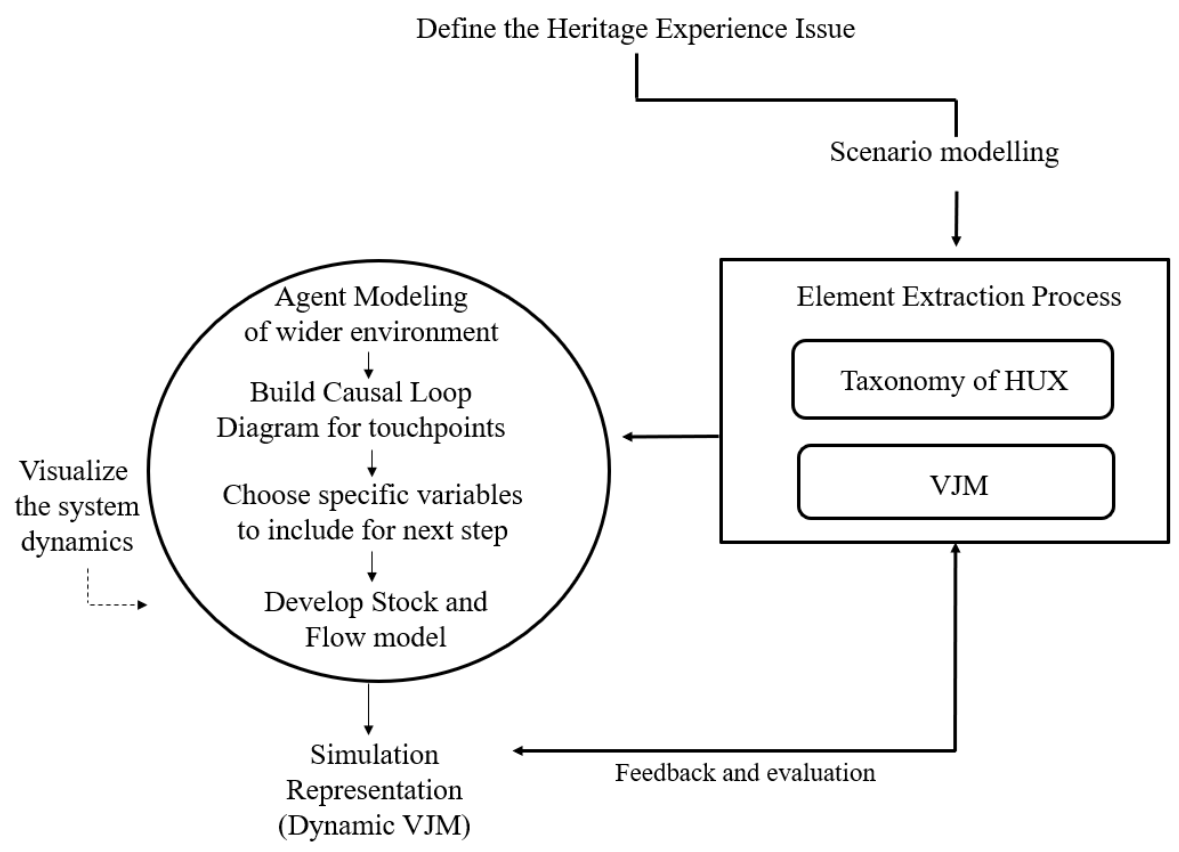

Figure 3: Framework for the design Heritage User Experiences and Simulation (HUXSIM). 


\section{AlSubhi and Bell}

Designing heritage user experiences (HUX) starts by defining the issue of interest, and the steps required to design and build the experience journey. The right hand side of the model depicts the visitor journey mapping process (design thinking), while the left side connects to the simulation modeling processes (system thinking). The model ultimately attempts to illustrate how to design a journey experience that can have a positive effect on increasing the number of visitors. These steps are described below:

- Persona of different types of visitors: The designer identifies the type of persona visiting (or targeted to visit) the museum or attraction.

- Journey Phases: The steps each persona is going through that define his/her experience.

- Emotional Representation: This reflects the emotional feeling of the persona experience journey at each phase.

- Touch points identification: Interactions with the user, including technological and more traditional signage.

- Design Visitors Journey Mapping: At this stage the designer creates a focus group to design the final journey with stakeholders or/and visitors.

- Scenario Modeling: The designer in this step builds a scenario that will be explored with simulation (in this case the movement between the county museum and Maiden Castle)

- Constructing an agent model to better understand the wider environment.

- Building the Casual Loop Diagram for interactions/touchpoints: This step reflects the above scenario and incorporates all elements that can be effect a specific interaction, whether positive or negative.

- Reflect and draw conclusion: The designer at this stage summarizes the main effects from the above step and takes them as an input into the final step.

- Develop Stock and Flow model: This is an important step that illustrates how the touchpoint design can influence visitor numbers (and revenue resulting) and represents variables that affect the increase or decrease of number of visitors.

The proposed methodology has a clear emphasis on working closely with the stakeholders in order to identify issues, create solutions and subsequently evaluate them. All data was collected from stakeholder meetings, including sessions after using the app at Maiden Castle. Hence, in the following sections, the paper will present the transformation process from VJM to Simulation.

\subsection{Visitor Journey Mapping (VJM)}

Persona represent a "character" with which client and design teams can engage in the design process (Stickdorn et al. 2011). Persona are also known as a model built after a comprehensive perception of a potential users (Pruitt and Adlin 2010). An appropriate balance must be achieved between contextual and all-encompassing knowledge, concerning emotional, subjective and lifestyle issues (Dubberly 2008). The narrative can become convoluted by possibly distracting points of interest/details (Alves and Nunes 2013; Pruitt and Grudin 2003). Other literature describes the persona as "a user representation intending to simplify communication and project decision making by selecting project rules that suit the real propositions" (Junior and Filgueiras 2005). However, a more precise definition that is in line with the objective of this research would be a combination of the first (Stickdorn et al. 2011) and last (Junior and Filgueiras 2005) definitions where the persona is a character used to simplify the communication and project decision-making. Persona are used to help the designers and programmers to understand clearly the user's needs and requirements (Lawton 1980). The method is used for the development of marketing products, so as to reflect the human perspective of DT (Stickdorn et al. 2011). It can help classify the user's requirements and desires (Chasanidou et al. 2015). In this study and as mentioned earlier, persona is used to provide guidance and give an overview about how the visitors are expected to interact with the museum. 


\section{AlSubhi and Bell}

A Customer Journey Map (CJM) is a digital design method that uses story based interaction with visualization of user experience. It includes formal and informal touchpoints, which represent many levels of factors affecting experience. The methodology is also a structured visual representation and similar to a visual language. CJM identifies problems and opportunities, taking into consideration personalization with pictures and photos (Stickdorn et al. 2011).

The dyadic view of the service encounter has been challenged for not recognizing the importance of factors outside the organization that contribute to customer experience (Verhoef et al. 2009; Gummesson, 2008). In addition, little importance is given to the coordination of service providers both within and across organizations to support customer satisfaction (Gittell 2002). Sampson (2012) points out that service processes frequently require identification of entities to address the customer's. Patricio et al. (2011) further develop external entities as containing "customer value constellation," and note that they are an important part of a multi-level service design process. These frameworks are consistent with articles on service innovation, growth, and experience management that contend that firms need to understand the concept of service from the perspective of the customer's overall requirements or goals (Tax et al. 2013). This includes identifying from the customers' perspective all the touchpoints that comprise the journey required to help them achieve their goals (Zomerdijk and Voss 2010). One clear result of advanced blueprinting and design approaches that map out the service from the customer's perspective is the recognition that the journey frequently involves touch points at multiple places of an organization and often with external partners as well (Sampson 2012; Patrício et al. 2011). Accordingly, in this study, it would be helpful to use CJM as one of the approaches to design processes (Tax et al. 2013).

Figure 4 presents an example output from a museum design thinking workshop- a jouney map. It represents the experience of a school teacher in booking a trip to a museum for his class. The goal of his trip was to find valuable information in a short time to maximize student learning. It can be seen in the journey map that the overall emotion shows the experience was not always ideal. Consequently, instead of collecting similar experiences simulation can be used to explore and analyze possible variation and associated impact. System modeling is then used as a collective process to realise and present the journey map.

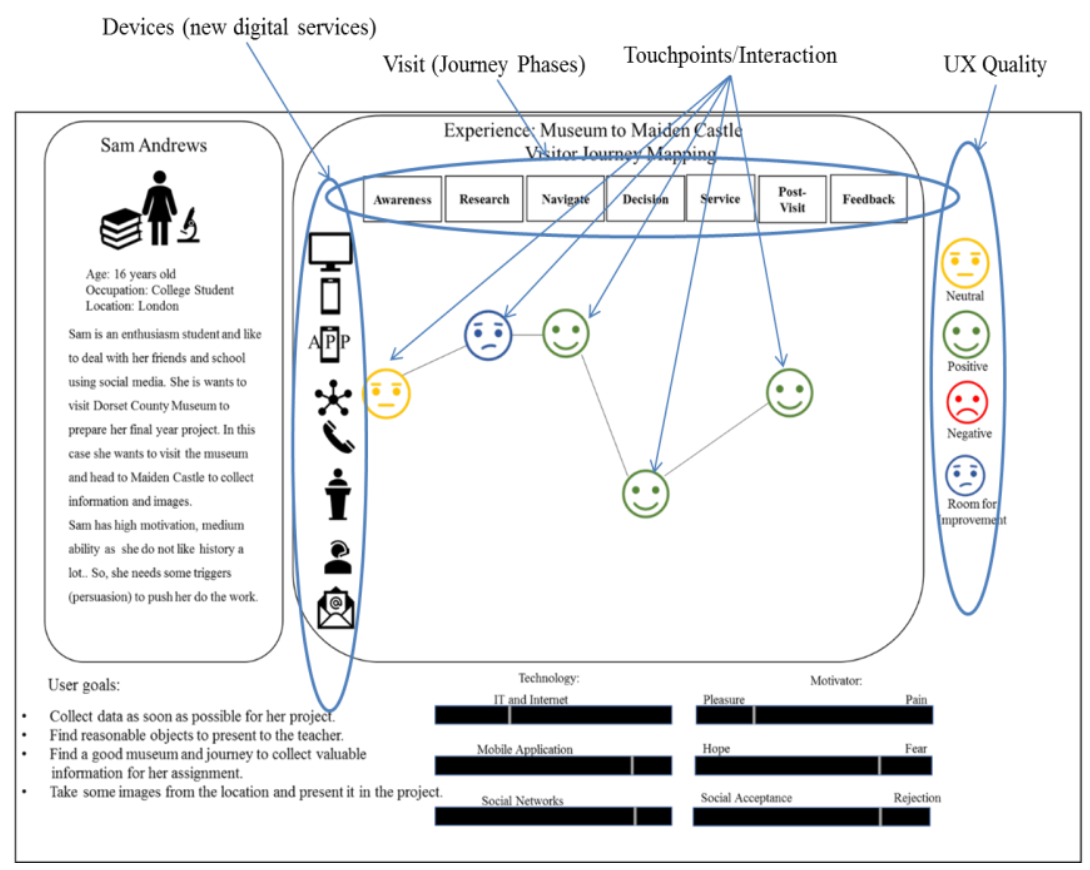

Figure 4: Visitor Journey (VJM) Experience - Student. 


\section{AlSubhi and Bell}

\section{MODELING VISITOR BEHAVIOUR}

\subsection{Wider Heritage Landscape}

The VJM, constructed during workshops with stakeholders, underpinned all modelling that took place. The sessions uncovered a number of key constructs: 1) Persona, 2) phases of the journey, 3) decision making, 4) emotion and 5) touchpoint modality. The hybrid approach enables modularization of this complex environment, with specific constructs being explored using different modelling paradigms. Phases of the journey and decision making are included in agent models where numbers of touchpoints and visitor attendance is explored. Subsequently, system dynamics methods are used to delve further into specific persona and their motivations, uncovering further detail on touchpoint preferences and external factors.

During the element extraction phase, instances of each construct are identified. Significant elements from the VJM are selected to build an agent model and then more focused causal loop diagrams (CLD). An agent model was initially constructed to investigate the touchpoint placement in the physical environment and their impact on word of mouth and visitor numbers. We were particularly interested in the links between the county museum (blue circle) and Maiden Castle (blue square) - see figure 5. In this model the user is able to experiment with the number of touchpoints as well as the likelihood of visitors at one venue to attend the other venue.

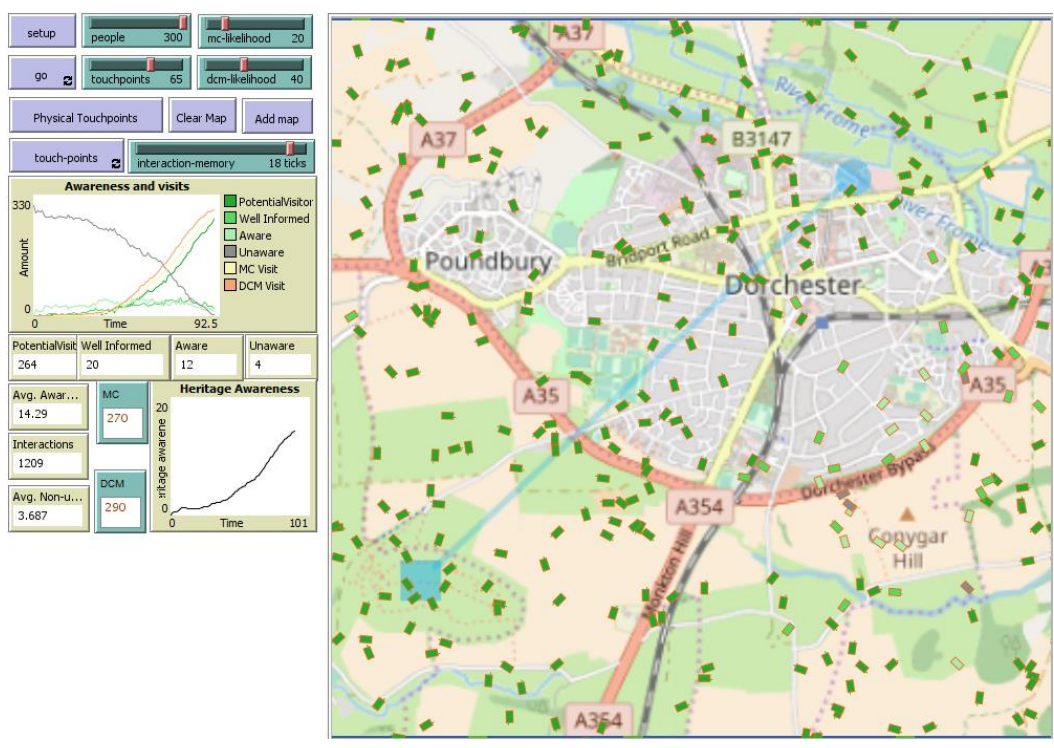

Figure 5: Agent modelling of touchpoint impact on the wider environment.

\subsection{Visitor Experience Dynamics}

Touchpoints can take a number of forms, from signage to smartphone push notifications. Designing specific interactions requires further depth, specifically around visitor motivations. An appropriate method to uncover what affects groups of visitors (persona) is to use system dynamics to simulate the visitor experience, as real-life observations will require more time. CLD is a used in the first instance, a method of analysis used to develop an understanding of this complex systems of personas and specific touchpoints. Using the CLD as a tool helps to visualize as well as developing an understanding of complex systems. It is a language which helps to present an understanding of the dynamic, interconnected nature of a world (Qudrat-Ullah 2010; Kim 1992), and is constructed as sentences linked together by key variables with 


\section{AlSubhi and Bell}

causal relationships between them. It creates a coherent story about a problem or an issue, showing different loops, therefore using CLDs as a tool helps to visualize visitor experience and motivations.

The first step is the identification of the main touchpoints and channels in a VJM, together with a list of activities that a user/visitor performs during their journey, such as: (1) researching an object or experience through an appropriate channel; (2) obtaining an object or experience through an appropriate channel; (3) getting help/support/customer service for an object they found through an appropriate channel; and (4) an experience is delivered or performed (Sandler 2015). At each touchpoint, visitor behaviours and feelings differ with their experiences of the heritage journey. These emotional states need to be understood and applying CLD helps to identify inflow and outflow of a visit later during the developemnt of a SFM. The components in building a CLD are presented in Kunc (2016) and Qudrat-Ullah (2010) which adopted from (Kim 1992; Forrester 1961; Forrester, 1994; Sterman 2000).

Figure 6 represents all the factors that are present in the student visitor scenario and their inter-relations. For example, ticket cost has a negative impact during the decision making process. Similarly, as technology is widely used in museums (apps and digital services), a positive impact on the number of visitors would result. From the previous phases, it can be observed that the main variables in this problem are the new digital services, the visit and the quality of experience. These variables are grounded in the CJM and their influences emerge from workshop discussion around the journey map.

CLDs are created for each persona. Persona CLDs are reviewed for similarity (motivating common experience designs) and then used to build SFD (see figure 6) where core VJM variables are examined specifically new service designs and their potential impact. UX quality is the media quality consumed at a particular touchpoint - one example being augmented reality imagery.

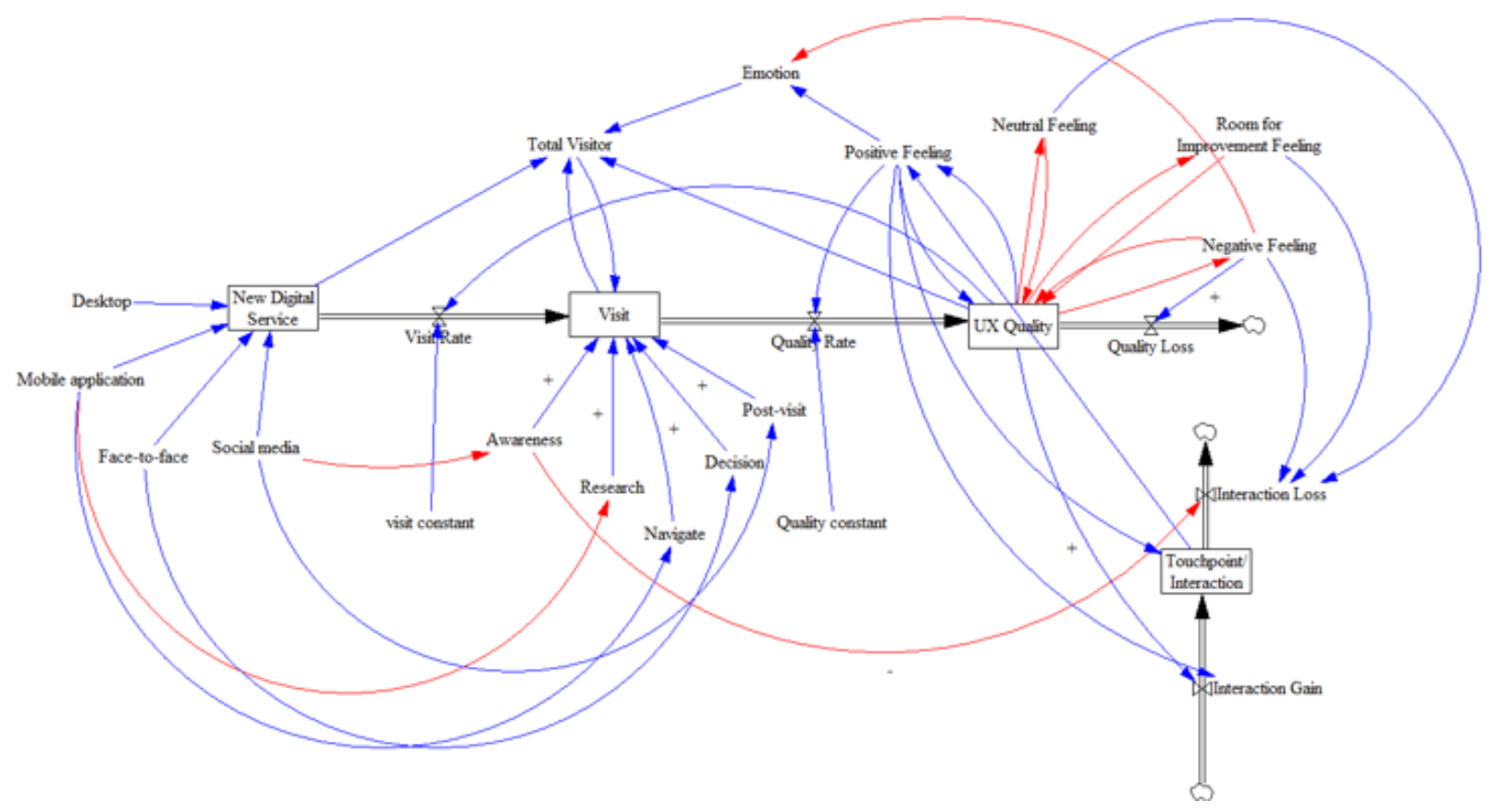

Figure 6: SFD exploring the student visit.

QoE reacts positively to technology investment and visitor emotion. On the other hand, the quality of Website and poor reception design impacts negatively the number of visitors. The importance of the visit start (previously identified as problematic using reception modelling) is explored using mobile app and social media interactions at the outset. 


\section{JOUNEY MAP TRANSFORMATION PROCESS}

Journey mapping underpins both simulation approach - providing a set of constructs (Table 1) from which to model. Persona are also underpin both paradigms, e.g. with agents for each persona. VJM constructs are modeled in the following manner:

Table 1: Core construct transformation.

\begin{tabular}{|l|l|l|}
\hline $\begin{array}{l}\text { VJM } \\
\text { Construct }\end{array}$ & Agent Model & SD Model \\
\hline Devices & $\begin{array}{l}\text { Visitor agent states in the } \\
\text { landscape }\end{array}$ & $\begin{array}{l}\text { Mobile applications, Web or social media } \\
\text { opportunities }\end{array}$ \\
\hline $\begin{array}{l}\text { Journey } \\
\text { Phases }\end{array}$ & Visitor agent state transitions & $\begin{array}{l}\text { Awareness, research, navigate, decision, service, } \\
\text { post-visit, feedback in relation to interaction } \\
\text { variables }\end{array}$ \\
\hline Touchpoints & $\begin{array}{l}\text { Agents in the landscape (proximity } \\
\text { to visitor agents is impactful) }\end{array}$ & $\begin{array}{l}\text { Visitor interaction variables associated with the } \\
\text { experience }\end{array}$ \\
\hline UX Quality & $\begin{array}{l}\text { Measurement at the individual } \\
\text { visitor agent and system level }\end{array}$ & $\begin{array}{l}\text { Outcome variable - Positive, Neutral, Room for } \\
\text { improvement and negative feeling of the visitor. }\end{array}$ \\
\hline
\end{tabular}

\section{CONCLUSION}

The design of user (visitor) experiences in an interlinked heritage physical environment is complex. Experiencing museum artefacts within the museum or digitally in the location from where they were found is different but can also motivate further exploration. This research demonstrates how heritage user experiences (HUX) can be designed and simulated in a collaborative manner, drawing on design and system thinking to better support diverse visitor motivations. HUXSIM has been evaluated using a number of scenarios - with student visits presented in this paper. Customer journey mapping is used to effectively visualize and consolidate stakeholder group thinking before the transformation of modelling elements into two symbiotic simulation paradigms and platforms. Agent based simulation is used to explore the wider environment (including Dorset County Museum in the UK and Maiden Castle a nearby hill fort) and visitor interaction with associated touchpoints. System dynamic modeling is used to uncover the motivations of specific visitor types (personas) and the impact on visitor number at each site. Key constructs are identified that link the journey mapping to each simulation paradigm as well as links between the simulations themselves.

\section{ACKNOWLEDGMENTS}

This work was funded in part by an Innovate UK project (Reference 131490) titled, "Interactive Social Experience Engine (iSEE) for History and Heritage - A Dorset Prehistoric Feasibility Study."

\section{REFERENCES}

Al Subhi, N., D. Bell, and P. Lashmar. 2015. "Location Based Modelling for Heritage Mobile Applications". In Proceedings of the 2015 UKAIS Conference, March $16^{\text {th }}-18^{\text {th }}$, Oxford, UK.

Alves, R. and N.J. Nunes. 2013. "Towards a Taxonomy of Service Design Methods and Tools". In Proceedings of the 2013 International Exploring Services Science Conference, 215-229. Heidelberg, Berlin: Springer. 


\section{AlSubhi and Bell}

Bae, K.M., K.S. Lee, and Y.S. Kim. 2014. "Relationship Between Service Design Tools and Service Innovation-Focused on Korean Healthcare Cases". Asia-pacific Journal of Multimedia Services Convergent with Art, Humanities, and Sociology, 4(2): 63-70.

Bakhshi, H. 2013. Digital Culture Report: How Arts and Cultural Organizations in England Use Technology. In: NATIVE magazine, Digital R\&D fund for the Arts. http://artsdigitalrnd.org.uk/digitalcultureresearch/, accessed: 15.12.2014.

Barlas, Y. 1996. "Formal Apects of Model Validity and Validation in System Dynamics". System dynamics review, 12(3):183-210.

Bishai, D., L. Q. Paina, D.H. Peters, and A.A. Hyder. 2014. "Advancing the Application of Systems Thinking in Health: Why Cure Crowds Out Prevention", Health research policy and systems, 12(1): 28.

Brown, T. 2009. Change by Design: How Design Thinking Transforms Organizations and Inspires Innovation. New York, USA: Harper Collins Business.

Chasanidou, D., A. Gasparini, and E. Lee. 2014. "Design Thinking Methods and Tools for Innovation in Multidisciplinary Teams". In Workshop Innovation in HCI, October 2014, Helsinki, Finland: NordiCHI, 27-30.

Chasanidou, D., A.A. Gasparini, and E. Lee. 2015. "Design thinking methods and tools for innovation", In International Conference of Design, User Experience, and Usability. August $2^{\text {nd }}-7^{\text {th }}$, Los Angeles, USA: Springer, 12-23.

Chahal, K., and T. Eldabi. 2008. "Applicability of hybrid simulation to different modes of governance in UK healthcare". In Proceedings of the $40^{\text {th }}$ Conference on Winter Simulation, December $7^{\text {th }}-10^{\text {th }} 2008$, 1469-1477. Miami, Florida: IEEE.

Dillard, J.P., and M. Pfau. 2002. The persuasion handbook: Developments in theory and practice. London: Sage Publications.

Dubberly, H. 2008. "ON MODELING: Design in the Age of Biology: Shifting from a Mechanical-Object Ethos to an Organic-Systems Ethos". Interactions 15(5):35-41.

Evans, G. 2013. Cuts survey 2013, In Museums association. www.museumsassociation.org, accessed 13.01.2015.

Fishwick, P. A. 2016. "Learning simulation models through physical objects". In Proceedings of the 2016 Winter Simulation Conference, 1559-1570. Piscataway, New Jersey: IEEE Press.

Floris, A., L. Atzori, and G. Ginesu. 2014 "Addressing un-interoperability issues in QoE models: Is a layered modelling effective?". In 2014 IEEE International Conference Communications Workshops (ICC), June $10^{\text {th }}-14^{\text {th }}$, Sydney, Australia, 563-568.

Fogg, B., E, Lee, and J. Marshall. 2002. "Interactive Technology and Persuasion". In The Handbook of Persuasion: Theory and Practice, edited by J.P. Dillard and M. Pfau. Thousand Oaks, CA: Sage.

Fogg, B. 2009. "A Behavior Model for Persuasive Design". In $4^{\text {th }}$ International Conference on Persuasive Technology, 40-47. New York, USA: ACM.

Forrester, J. W. 1961. Industry dynamics. Cambridge: Massachusetts.

Forrester, J.W. 1994. "System Dynamics, Systems Thinking, and Soft OR". System Dynamics Review, 10(2-3): 245-256.

García, L.M., A. Deserti, and C. Teixeira. 2013. "Service Design Tools as Frameworks in the Generation of Business Ideas an Action Research Case Study". In the 2013 IEEE Tsinghua International Design Management Symposium (TIDMS), December $1^{\text {st }}-2^{\text {nd }}$, Shenzhen, China, 338-344.

Gittell, J.H. 2002. "Relationships Between Service Providers and their Impact on Customers". Journal of Service Research 4(4): 299-311.

Gummesson, E. 2008. "Extending the Service-Dominant Logic: from Customer Centricity to Balanced Centricity". Journal of the Academy of Marketing Science 36(1):15-17.

Gurteen, D. 1998. "Knowledge, Creativity and Innovation". Journal of Knowledge Management 2(1): 513. 


\section{AlSubhi and Bell}

Halttu, K., M. Oduor, P. Tikka, and H. Oinas-Kukkonen. 2015. "About the Persuasion Context for BCSSs: Analyzing the Contextual Factors". In Proceedings of the $3^{\text {rd }}$ International Workshop on Behavior Change Support Systems (BCSS2015), June, Chicago, USA, 43-50.

Hincapie, M., C. Diaz, M. Zapata, and C. Mesias. 2016. "Methodological Framework for the Design and Development of Applications for Reactivation of Cultural Heritage: Case Study Cisneros Marketplace at Medellin, Colombia". Journal on Computing and Cultural Heritage (JOCCH) 9(2): 8.

Junior, P.T.A. and L.V.L Filgueiras. 2005. "User Modeling with Personas". In Proceedings of the 2005 Latin American Conference on Human-Computer Interaction, 277-282. New York, USA: ACM.

Kim, C. S., and S. J. Chung. 2011. "Daylighting Simulation as an Architectural Design Process in Museums Installed with Toplights". Journal on Building and Environment 46(1): 210-222.

Kim, D. H. 1992. “Guidelines for Drawing Causal Loop Diagrams”. The Systems Thinker 3(1): 2.

Kunc, M. 2016. "System Dynamics: A Behavioral Modeling Method". In Proceedings of the 2016 Winter Simulation Conference, 53-64. Piscataway, New Jersey: IEEE Press.

Lawton, D. 1980. "Skelton's Use of Persona”. Journal on Essays in Criticism 30(1): 9-28.

March, S.T. and G.F. Smith. 1995. "Design and Natural Science Research on Information Technology". Journal on Decision Support Systems 15(4): 251-266.

Oinas-Kukkonen, H. 2013. "A Foundation for the Study of Behavior Change Support Systems". Journal on Personal and Ubiquitous Computing 17(6):1223-1235.

Oinas-Kukkonen, H. and M. Harjumaa. 2008. "Towards Deeper Understanding of Persuasion in Software and Information Systems". In Proceedings of the 2008 First International Conference on Advances in Computer-Human Interaction, 200-205. Washington, USA: IEEE.

Padilla-Meléndez, A. and A.R. del Águila-Obra. 2013. "Web and Social Media Usage by Museums: Online Value Creation". International Journal of Information Management 33(5): 892-898.

Patrício, L., R.P. Fisk, J. Falcão e Cunha, and L. Constantine. 2011. "Multilevel Service Design: From Customer Value Constellation to Service Experience Blueprinting". Journal of Service Research 14(2):180-200.

Pluchino, A., C. Garofalo, G. Inturri, A. Rapisarda, and M. Ignaccolo. 2014. "Agent-Based Simulation of Pedestrian Behaviour in Closed Spaces: A Museum Case Study". Journal of Artificial Societies and Social Simulation 17(1): 16.

Pruitt, J. and T. Adlin. (2010) The persona lifecycle: keeping people in mind throughout product design. London: Morgan Kaufmann, Elsevier.

Pruitt, J. and J. Grudin. 2003. "Personas: Practice and Theory". In Proceedings of the 2003 conference on Designing for user experiences, 1-15. New York, USA: ACM.

Qudrat-Ullah, H. 2010. "Perceptions of the Effectiveness of System Dynamics-Based Interactive Learning Environments: An Empirical Study". Computers \& Education 55(3):1277-1286.

Sampson, S.E. 2012. "Visualizing Service Operations". Journal of Service Research 15(2):182-198.

Sandler, J. 2015. "What users want: Functional user experience". In Proceedings of 2015 International Conference on Interactive Collaborative Learning (ICL), 355-360. IEEE.

Simon, H.A. 1996. The Sciences of the Artificial. London: MIT Press.

Stickdorn, M., J. Schneider, K. Andrews, and A. Lawrence. 2011. This is service design thinking: Basics, tools, cases. New Jersey: Wiley Hoboken.

Sterman, J. D. 2000. Business Dynamics: Systems Thinking and Modeling for a Complex World. Boston: Irwin/McGraw-Hill.

Tax, S.S., D. McCutcheon, and I.F. Wilkinson. 2013. "The Service Delivery Network (SDN) a CustomerCentric Perspective of the Customer Journey". Journal of Service Research 16(4): 454-470.

Verhoef, P.C., K.N. Lemon, A. Parasuraman, A. Roggeveen, M. Tsiros and L.A. Schlesinger. 2009. "Customer Experience Creation: Determinants, Dynamics and Management Strategies". Journal of Retailing 85(1): 31-41. 


\section{AlSubhi and Bell}

Von Alan, R.H., S.T. March, J. Park, and S. Ram. 2004. "Design Science in Information Systems Research". MIS quarterly 28(1): 75-105.

West, M.A., C.S. Borrill, J.F. Dawson, F. Brodbeck, D.A. Shapiro, and B. Haward. 2003. "Leadership Clarity and Team Innovation in Health Care". The Leadership Quarterly 14(4): 393-410.

Zomerdijk, L.G. and C.A. Voss. 2010. "Service Design for Experience-Centric Services" Journal of Service Research 13(1): 67-82.

\section{AUTHOR BIOGRAPHIES}

Nada (Nidaa) Nasser Al Subhi is a PhD candidate in the Department of Computer Science at Brunel University London. Her primary research interest is the design of User Experience and its applications within museums and education. She is also interested in the application of simulation as a tool to examine the impact of experience design with visitors and wider stakeholder groups.

Dr David Bell is a Senior Lecturer in the Department of Computer Science at Brunel University London where he carries out research into digital service design -simulating user interactions and behavioral change. Dr. Bell spent 15 years working in the IT industry (primarily within Investment Banking) in roles from developer to technology director. Dr. Bell is the Education Chair for the ACM SIGSIM where he is involved in the promotion and support of doctoral simulation researchers. 